BMC

Microbiology

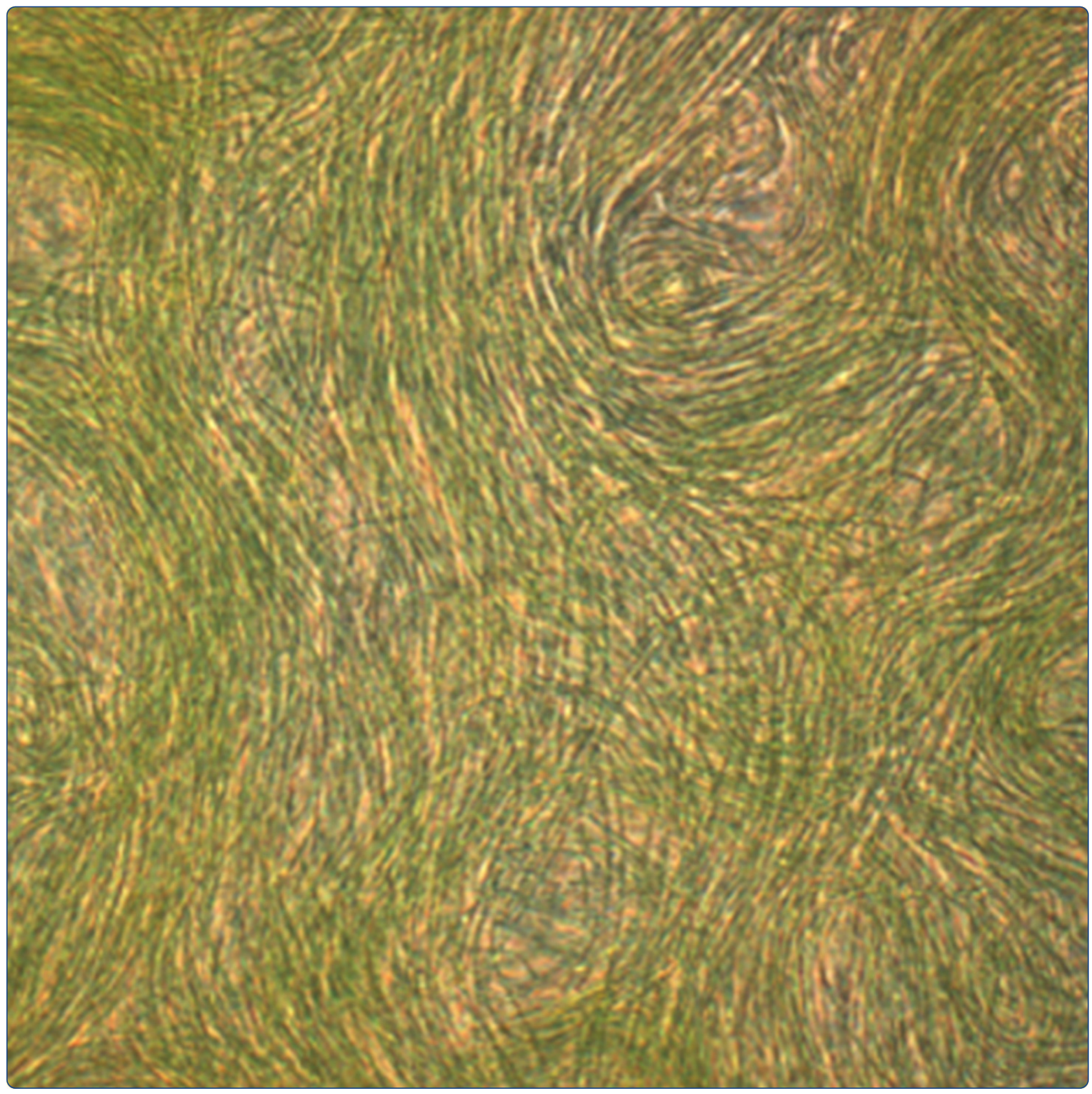

\title{
Gene copy number variation and its significance in cyanobacterial phylogeny
}

Schirrmeister et al. 


\title{
Gene copy number variation and its significance in cyanobacterial phylogeny
}

\author{
Bettina E Schirrmeister ${ }^{1,2^{*}}$, Daniel A Dalquen ${ }^{3,4}$, Maria Anisimova ${ }^{3,4}$ and Homayoun C Bagheri ${ }^{1}$
}

\begin{abstract}
Background: In eukaryotes, variation in gene copy numbers is often associated with deleterious effects, but may also have positive effects. For prokaryotes, studies on gene copy number variation are rare. Previous studies have suggested that high numbers of rRNA gene copies can be advantageous in environments with changing resource availability, but further association of gene copies and phenotypic traits are not documented. We used one of the morphologically most diverse prokaryotic phyla to test whether numbers of gene copies are associated with levels of cell differentiation.

Results: We implemented a search algorithm that identified 44 genes with highly conserved copies across 22 fully sequenced cyanobacterial taxa. For two very basal cyanobacterial species, Gloeobacter violaceus and a thermophilic Synechococcus species, distinct phylogenetic positions previously found were supported by identical protein coding gene copy numbers. Furthermore, we found that increased ribosomal gene copy numbers showed a strong correlation to cyanobacteria capable of terminal cell differentiation. Additionally, we detected extremely low variation of $16 \mathrm{~S}$ rRNA sequence copies within the cyanobacteria. We compared our results for $16 \mathrm{~S}$ rRNA to three other eubacterial phyla (Chroroflexi, Spirochaetes and Bacteroidetes). Based on Bayesian phylogenetic inference and the comparisons of genetic distances, we could confirm that cyanobacterial 16S rRNA paralogs and orthologs show significantly stronger conservation than found in other eubacterial phyla.

Conclusions: A higher number of ribosomal operons could potentially provide an advantage to terminally differentiated cyanobacteria. Furthermore, we suggest that $16 \mathrm{~S}$ rRNA gene copies in cyanobacteria are homogenized by both concerted evolution and purifying selection. In addition, the small ribosomal subunit in cyanobacteria appears to evolve at extraordinary slow evolutionary rates, an observation that has been made previously for morphological characteristics of cyanobacteria.
\end{abstract}

Keywords: Prokaryotic phylogenetics, Concerted evolution, Gene copy number variation, Ribosomal rRNA, Cyanobacterial morphology, Gloeobacter violaceus

\section{Background}

Many genes originated via gene duplication in both prokaryotes and eukaryotes. Evolution after gene duplication can follow several scenarios [1]. Subfunctionalization leads to gene copies evolving specialized functions, all of which are necessary for performing the original gene function. In the neofunctionalization scenario, one gene copy is preserved by purifying selection, while the other copy may evolve a novel function through rapid adaptation. Finally, in a process known as pseudogenization, one gene copy will lose its function due to accumulation of mutations. Another possible evolutionary fate for

\footnotetext{
*Correspondence: bettina.Schirrmeister@bristol.ac.uk

${ }^{1}$ Institute of Evolutionary Biology and Environmental Studies, University of

Zurich, Winterthurerstr. 190, 8057 Zurich, Switzerland

${ }^{2}$ School of Earth Sciences, University of Bristol, Wills Memorial Building,

Queens Road, Bristol BS8 1RJ, UK

Full list of author information is available at the end of the article
}

gene duplicates is gene conservation. Conserved gene copies can be easily detected based on their high levels of sequence similarity, which typically occurs for genes whose products are needed in high concentrations. All gene copies are strongly expressed in such cases. Gene duplicates can maintain their identical function in two ways: by purifying selection which prevents the duplicates from diverging, or alternatively through concerted evolution where frequent gene conversion maintains sequence identity within the genome [1].

Gene copy number variants have been frequently found and studied in humans [2], but are also known to exist in other eukaryotic organisms, such as mouse [3], maize [4], and yeast [5]. Studies on human copy number variants revealed that multiple gene copies are often associated with diseases [6,7], but can also have positive effects as has been shown for salivary amylase genes [8]. Less is known about consequences of protein coding gene copy number 
variations in prokaryotes. Though there have been studies on variation of ribosomal RNA gene copy numbers and possible consequences $[9,10]$. Bacteria exhibiting multiple rRNA gene copies seem to respond faster to resource availability [11]. Accelerated growth rate has been conjectured to be a result of high ribosomal copy numbers [12]. In E. coli it is known that more than one rRNA operon has to be functional to express sufficient ribosomes and achieve maximum growth. Bacteria generally possess fewer than 10 rRNA gene copies [13], though some Proteobacteria and Firmicutes may have as many as 15 copies of rRNA operons [10]. Furthermore, ribosomal RNA copy numbers have been suggested to be phylogentically informative [14]. Phylogenetic positions of organisms and the amount of rRNA operon copy numbers they possess are generally associated.

Although potentially important effects of ribosomal copy numbers have been suggested in various studies, protein coding gene copies are less considered. This could be due to the assumption that selection for faster cell replication leads to genome reduction in prokaryotes [15], which would reduce the likelihood of survival of multiple gene copies. Indeed, a tendency towards genome reduction has been observed in endosymbiotic bacteria, and in free living prokaryotes including unicellular marine cyanobacteria [16]. However, conclusions that contradict this have been made by Kou and colleagues [17] who suggest that a lack of large prokaryotic genomes could be the result of selection acting on an upper limit of genome size. Thus, if there is no selective genome reduction in prokaryotes, multiple gene copies might be more widely distributed and of greater importance for prokaryotes than is believed so far.

Among prokaryotes cyanobacteria depict one of the morphologically most diverse phyla. Several of their morphotypes seem to exist for over two billion years as indicated by a well preserved fossil record $[18,19]$. Cyanobacteria inhabit diverse environments. They had (and still have) an exceptional influence on the planet due to their ability to conduct oxygenic photosynthesis and fix nitrogen. According to their morphology, cyanobacteria have been classified into five different sections [20], though molecular data indicate that probably none of the five groups is monophyletic [21-26]. Section I and II consist of unicellular cyanobacteria. Section II species can be distinguished from all other cyanobacteria based on their reproduction via multiple fission. Cyanobacteria belonging to section III to $\mathrm{V}$ exhibit filamentous growth. Across the five existing morphotype sections cyanobacteria exhibit several patterns of differentiation. The majority of extant cyanobacterial species control gene expression using a circadian clock. Additionally, several multicellular cyanobacteria developed mechanisms to differentiate not only temporarily, but also spatially.
Trichodesmium is the only section III genus known, able to produce specialized cells ('diazocytes') in the middle of a filament [27-29]. The principal form of terminal cell differentiation is observed in section IV and V cyanobacteria. Given the morphological variety found in this phylum, we ask whether gene dosage (multiple gene copies per cell) is associated with adaptive morphological strategies such as cell differentiation in cyanobacteria. Variation in 16S rRNA gene copy sequences and numbers has been reported previously for cyanobacterial genera [30,31], but no phenotypic correlations were found. Little is known about protein coding gene copy numbers in cyanobacteria.

In this study we searched for both ribosomal RNA and protein coding gene copy number variation in diverse species of cyanobacteria for which full genome sequences were available. Ribosomal RNA gene copies were examined since it is known that they might occur in multiple copies and exhibit gene dosage effects [11-13]. Segments of genes within the rRNA operon are strongly conserved because of their functional relevance [32]. These unique features have made $16 \mathrm{~S}$ rRNA gene sequences a favored taxonomic marker for prokaryotes [33]. Although rRNA sequence variation within a genome is low for most species [9], considerable intragenomic differences have been reported in some non-cyanobacterial species $[10,34]$. This has led to the questioning of the reliability of 16S rRNA genes as a taxonomic marker. We examined sequence identity of rRNA genes within species of cyanobacteria by conducting phylogenetic analyses and calculating phylogenetic distances. Results for cyanobacteria were compared to data from the prokaryotic phyla Chroroflexi, Spirochaetes, and Bacteroidetes. Paralogs of $16 \mathrm{~S}$ rRNA genes are almost identical in cyanobacterial species and suggest a deviation from divergent evolution of gene copies. Investigating variation in copies of the internal transcribed spacer region (ITS), located between the $16 \mathrm{~S}$ and $23 \mathrm{~S}$ rRNA genes, suggests that both concerted evolution and purifying selection are viable hypotheses for the evolution of $16 \mathrm{~S}$ rRNA in cyanobacteria. Furthermore, we observed an exceptionally strong sequence conservation in 16S rRNA orthologs within the cyanobacterial phylum. A level of conservation that could not be observed in any of the eubacterial phyla studied here.

\section{Results and discussion}

\section{Identification of conserved gene copies and their phylogenetic relevance}

Aside from ribosomal RNA genes, we identified 41 protein coding genes which possess multiple conserved gene copies in at least one cyanobacterial species (Additional file 1). From this total of 44 genes, only six showed significant correlations to morphological characteristics. Ribosomal RNA genes were the main class of genes exhibiting 
conserved gene copies that were significantly correlated to the cyanobacterial sections IV and V. Species capable of terminal cell differentiation exhibited four or five copies of ribosomal genes. Furthermore, Gloebacter violaceus and a thermophilic Synechococcus species share a distinct pattern of gene copy numbers which adds independent support to previous studies that have grouped these species separately from the rest of cyanobacteria, closer to an eubacterial outgroup [22,35-39].

We investigated conserved gene copies that exhibited $\geq 90 \%$ (not shown), $\geq 95 \%$ (not shown) and $\geq 98 \%$ amino acid sequence identity within a genome. Results varied mainly in numbers of transposase gene copies detected. Therefore, results of gene copies with an identity of $\geq 98 \%$ within a genome and $\geq 50 \%$ between species are presented here. For these genes, we mapped copy numbers in relation to the phylogenetic position within cyanobacteria (Figure 1). The highest number of gene copies (24) was found for a transposase encoding gene in Microcystis aeruginosa. Transposases are enzymes that catalyze the movement of transposable elements. Previous studies have estimated that genes encoding for trans- posases are the most widespread genes, and often occur as multiple copies [40]. Almost half of the conserved gene copies identified in this study were transposase encoding genes. The frequency of transposase genes varied between different species. Microcystis aeruginosa possessed various transposase genes, whereas strains belonging to the genera Synechococcus and Prochlorococcus, and Cyanobacterium sp. UCYN-A seem to exhibited fewer transposase gene copies.

Synechococcus sp. JA-3-3Ab, a unicellular cyanobacterium isolated from a hot spring in Yellow Stone National Park $[41,42]$, exhibited a pattern of gene copy numbers that generally deviated from the pattern observed in other Synechococci. It shared identical copy numbers of protein coding genes with Gloeobacter violaceus. These included a series of not yet annotated genes missing in all other cyanobacteria. This pattern of almost identical conserved gene copy numbers supports other phylogenetic and phylogenomic studies that place these two species close to each other at the base of the cyanobacterial phylogenetic tree [36-38]. In a previous study using $16 \mathrm{~S}$ rRNA sequences, Schirrmeister et al. [39] observed a close

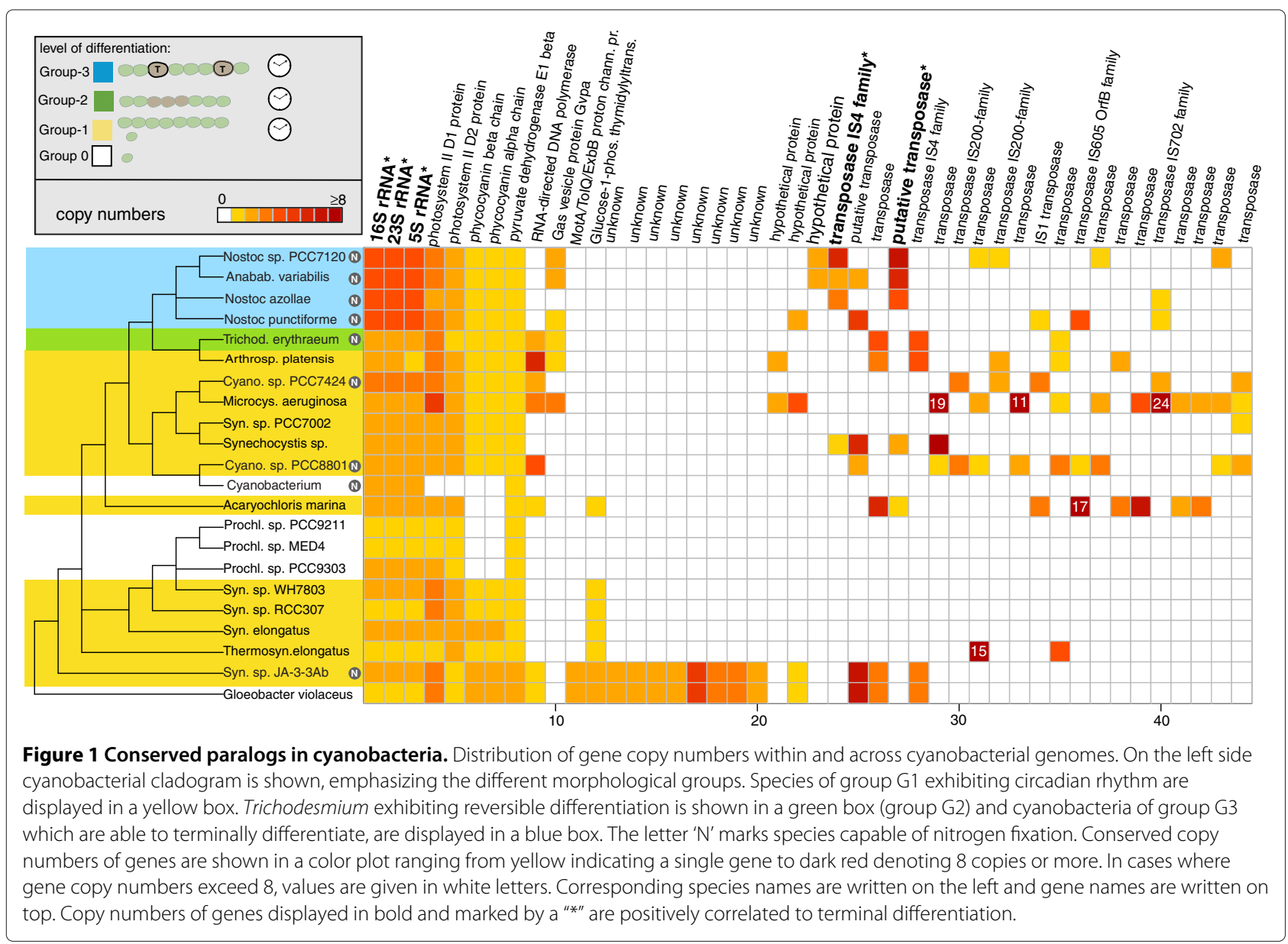


phylogenetic relationship of Gloeobacter violaceus and another Synechococcus strain [43] isolated from the same source as Synechococcus $s p$. JA-3-3Ab. Similar results have been found elsewhere [22]. The phylogenetic distance of Gloeobacter violaceus to other extant cyanobacteria has been pointed out before [35]. Major differences involve the light harvesting machinery. Gloebacter violaceus lacks thylacoid membranes [44], and various genes from photosystems I and II.

Furthermore, we identified several genomes with more than one ribosomal gene copies. Cyanobacterial taxa used in this study exhibited one to four conserved rRNA gene copies (Figure 1, Table 1). Position of ribosomal gene copy numbers across the Bayesian tree were phylogenetically non-informative (Figures 1 and 2). However, four rRNA copies could only be observed in terminally differentiated species. Additional data on $16 \mathrm{~S}$ rRNA copy numbers shown in the rrn-database, confirmed these findings and furthermore reported five copies for several cyanobacterial species belonging to sections IV and V. Aside from $16 \mathrm{~S}$ rRNA data, no further information was obtained, because these taxa have not been fully sequenced, yet [45].

\section{Correlation of copy numbers to terminal differentiation}

To confirm possible associations of ribosomal RNA copy numbers to species capable of terminal cell differentiation, we visualized the distribution of ribosomal gene copy numbers and tested for possible correlations to morphotypes (Figure 3). We additionally calculated potential correlations of all protein coding gene copy numbers identified in this study with morphotypes. Therefore, we divided cyanobacteria into four morphological groups according to their mode of differentiation. Group 0 (G0) exhibits no mode of differentiation and contains solely unicellular species. Group 1 (G1) consists of species from section I to III which control gene expression via a circadian rhythm, but lack any other form of differentiation. Group 2 (G2) is formed exclusively by the genus Trichodesmium which is able to form temporarily differentiated cells for nitrogen fixation. The last group (G3) contains species from section IV and $\mathrm{V}$ which are able to produce terminally differentiated cells.

Using Spearman's rank correlation coefficient $(\rho)$ and Pearson's correlation coefficient $(\mathrm{R})$, we estimated a potential correlation of copy numbers to the defined morphological groups. Both tests indicated significant correlations to morphological groups for all ribosomal genes and two transposase coding genes. Furthermore, Spearman's $\rho$ attested a significant correlation to morphology for photosystem II reaction center D2 protein $(\rho=0.62)$, and a weaker correlation to Gas vesicle protein GVPa $(\rho=0.58)$ coding genes. A significant Pearson's correlation was found for a gene coding for a hypothetical protein
$(R=0.58)$. In Figure 3 distributions of ribosomal RNA gene copy numbers across morphological groups are presented as boxplot graphics with correlation coefficients, and p-values shown. All taxa capable of terminal differentiation exhibited four copies of ribosomal RNA genes. Correlation coefficients for $16 \mathrm{~S}$ and $23 \mathrm{~S}$ rRNA genes were $\rho=0.74 / \mathrm{R}=0.86$, in both cases, and $\rho=0.63 / \mathrm{R}=0.8$ for the $5 \mathrm{~S}$ rRNA genes. Including additional data from the rrn-database [45] (Additional file 2), resulted in an even stronger correlation of $16 \mathrm{~S}$ rRNA gene copy numbers to cyanobacterial species capable of terminal differentiation ( $\rho=0.87 / R=0.9$; Additional file 3). Cyanobacteria belonging to section IV and V form terminally differentiated cells (called heterocysts) in the absence of fixed nitrogen. In these cells oxygen sensitive nitrogen fixation can take place while neighbouring cells conduct oxygenic photosynthesis. These heterocystous cells undergo various structural and physiological alterations to protect nitrogenase from oxygen in a 'microanaerobic' environment. As a result they lose their ability to conduct photosynthesis and to divide. Multiple rRNA gene copies could have positive effects during heterocyst formation, the same way as they help E.coli to achieve maximum growth [12], and increases responses to changing environmental conditions [11]. An increased amount of functional ribosomal operons likely depicts an advantage in the process of cell differentiation, during which expression of various genes is upregulated [46].

\section{Strong conservation of 16S rRNA copies}

Previous studies have sometimes questioned the potential of $16 \mathrm{~S}$ rRNA gene sequences as a taxonomic marker due to variation that has been observed between gene paralogs in some non-cyanobacterial organism [10,34]. We explored sequence variation of $16 \mathrm{~S}$ rRNA genes in cyanobacteria by reconstructing phylogenetic trees with Bayesian inference. We evaluated the divergence of $16 \mathrm{~S}$ rRNA gene copies within and between cyanobacterial taxa. The inferred Bayesian consensus tree is displayed in Figure 2. Investigated cyanobacteria, exhibit one to four $16 \mathrm{~S}$ rRNA copies per genome. Unicellular species partition in two major groups: species belonging to the marine pico-phytoplankton genera Synechococcus and Prochlorococcus, and members of the genera Synechocystis, Cyanothece and Microcystis which show a closer relation to multicellular cyanobacteria. All multicellular species studied here are closely related, and species capable of terminal differentiation form a monophyletic group. Comparisons of our study to previous findings show high similarities. Our results agree with a comparative phylogenomics approach used by Swingley et al. [36], a consensus tree of concatenated sequences presented by Blank and Sànchez-Baracaldo [47], and, are highly similar to $16 \mathrm{~S}$ rRNA analyses conducted by Schirrmeister 
Table 1 Data of cyanobacterial 16S rRNA gene sequences

\begin{tabular}{|c|c|c|c|c|c|c|c|c|c|}
\hline Species & Group & Genome size & \# of copies & $d^{1}$ & $\mathbf{F}$ & $\mathbf{F}$ & $\mathbf{R}$ & $\mathbf{R}$ & Accession $\mathrm{nr}$. \\
\hline Acharyochloris marina MBIC11017 & G1 & 8.36 & 2 & 0 & $5,636,175$ & & $1,409,149$ & & CP000828.1 \\
\hline Anabaena variabilis ATCC 29413 & G3 & 7.10 & 4 & 0 & $1,002,918$ & $3,894,075$ & $2,808,379$ & $5,435,874$ & СР000117.1 \\
\hline Arthrospira platensis NIES 39 & G1 & 6.80 & 2 & 0 & & & $2,584,861$ & $3,509,612$ & AP011615 \\
\hline Cyanothece sp. PCC 7424 & G1 & 6.52 & 3 & 0.001 & $1,328,842$ & $3,465,297$ & $2,494,023$ & & СР001291.1 \\
\hline Cyanothece sp. PCC 8801 & G1 & 4.81 & 2 & 0 & $3,806,018$ & & $2,484,826$ & & СР001287.1 \\
\hline Gloeobacter violaceus PCC 7421 & Go & 4.70 & 1 & & & & $1,571,231$ & & BA000045.2 \\
\hline Microcystis aeruginosa NIES-843 & G1 & 5.80 & 2 & 0.003 & $1,885,807$ & & $3,597,272$ & & AP009552.1 \\
\hline Nostoc azollae 0708 & G3 & 5.53 & 4 & 0 & 830,919 & $2,217,271$ & 979,079 & $2,979,417$ & СР002059.1 \\
\hline Nostoc punctiforme PCC 73102 & G3 & 9.01 & 4 & 0.002 & $2,021,489$ & $6,085,170$ & $5,515,629$ & $6,502,973$ & СР001037.1 \\
\hline Nostoc sp. PCC 7120 & G3 & 7.20 & 4 & 0 & $2,375,734$ & $2,500,525$ & $4,918,283$ & $5,945,700$ & BA000019.2 \\
\hline Prochlorococcus marinus MIT 9211 & G0 & 1.70 & 1 & & 342,283 & & & & СР000878.1 \\
\hline Prochlorococcus marinus MIT 9303 & G0 & 2.70 & 2 & 0 & 243,682 & & $1,938,786$ & & СР000554.1 \\
\hline P. marinus subsp. pastoris str. CCMP1986 (MED) & G0 & 1.70 & 1 & & 313,061 & & & & BX548174.1 \\
\hline Synechococcus elongatus PCC 6301 & G1 & 2.70 & 2 & 0 & $1,656,455$ & & $1,050,801$ & & AP008231.1 \\
\hline Synechococcus sp. JA-3-3Ab & G1 & 2.90 & 2 & 0 & $2,310,397$ & & $1,110,127$ & & CP000239.1 \\
\hline Synechococcus sp. PCC 7002 & G1 & 3.40 & 2 & 0 & $1,461,361$ & & $2,909,371$ & & CP000951.1 \\
\hline Synechococcus sp. RCC307 & G1 & 2.20 & 1 & & 348,765 & & & & СТ978603.1 \\
\hline Synechococcus sp. WH 7803 & G1 & 2.40 & 2 & 0 & 534,563 & & $2,019,450$ & & СТ971583.1 \\
\hline Synechocystis sp. PCC 6803 & G1 & 3.97 & 2 & 0 & $3,325,053$ & & 245,2187 & & BA000022.2 \\
\hline Thermosynechococcus elongatus BP-1 & G1 & 2.59 & 1 & & & & $2,335,243$ & & BA000039.2 \\
\hline Trichodesmium erythraeum IMS101 & G2 & 7.80 & 2 & 0 & $3,137,164$ & & $4,601,878$ & & СР000393.1 \\
\hline Cyanobacterium UCYN-A & G0 & 1.40 & 2 & 0 & 638,681 & & 3,507 & & СР001842.1 \\
\hline
\end{tabular}

$\mathrm{d}^{1}$ : Largest distance between gene copies within the genome. F: Coordinates for the 16S rRNA genes on the forward strand of the chromosome. R: Coordinates for the 16S rRNA genes on the reverse strand of the chromosome. 

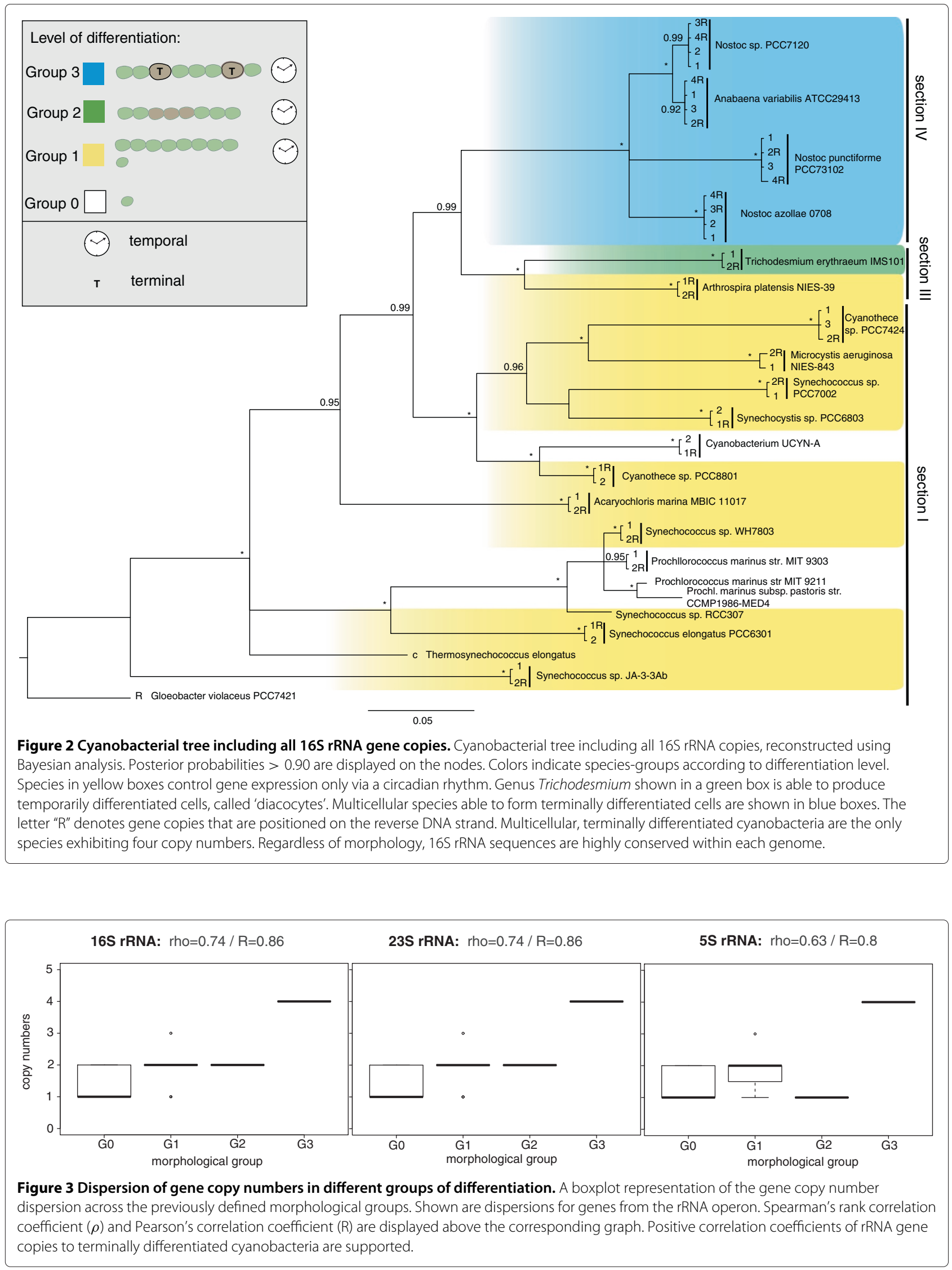
et al. [39]. Using a larger taxon set [39], we previously inferred polyphyletic groupings of undifferentiated multicellular species belonging to section III. This however is not deducible from the taxonomically more limited full genome data set used in the present study.

In cyanobacteria $16 \mathrm{~S}$ rRNA sequences were highly conserved within a genome. Three species showed minor nucleotide differences. The two 16S rRNA copies of Microcystis aeruginosa differed by four 'single nucleotide polymorphisms' (SNPs), in Cyanothece sp. PCC 7424 one SNP was detected, and in Nostoc punctiforme one $16 \mathrm{~S}$ copy possessed two SNPs. The differences are visualized in a molecular distance matrix in Figure 4. 16S rRNA copies within species were identical for the majority of taxa (shown in yellow) and can be clearly distinguished from gene copies belonging to different species. Furthermore, using the whole dataset we calculated mean distances within strains $\left(d_{W}\right)$ and between strains $\left(d_{B}\right)$. Results are presented in Table 2. Significance of differences in sequence distances found within and between cyanobacterial strains were estimated using bootstrap re-sampling of the original data set. Distributions of the resulting mean distances are displayed in Additional files 4 and 5 . For each distribution, an overall mean distance was calculated $\left(d_{W}^{*}, d_{B}^{*}\right)$. Mean distance of $16 \mathrm{~S}$ rRNA sequences within species $\left(d_{W}=0.0001\right)$ is significantly smaller than between species $\left(d_{B}=0.14\right.$; Table 2$)$. $95 \%$ confidence intervals of distributions obtained by re-samplings do not overlap. Although previous studies have claimed that variation within $16 \mathrm{~S}$ rRNA sequences might affect reliability of this gene as a taxonomic marker [10,34], this was not found for genera used in this study. Rather, the extreme sequence conservation of $16 \mathrm{~S}$ rRNA gene copies from the same species supports $16 \mathrm{~S}$ rRNA as a reliable genetic marker for the taxa analyzed here.

In order to verify the significance of our results for cyanobacteria, we compared phylogenetic and distance results from the cyanobacteria to three eubacterial phyla (Chroroflexi, Spirochaetes and Bacteroidetes). Figure 5 presents the Bayesian consensus phylogenetic tree and the distance matrix reconstructed for the phylum Chloroflexi. Trees and distance matrices for the phyla Spirochaetes, and Bacteroidetes are shown in Additional files 6, 7

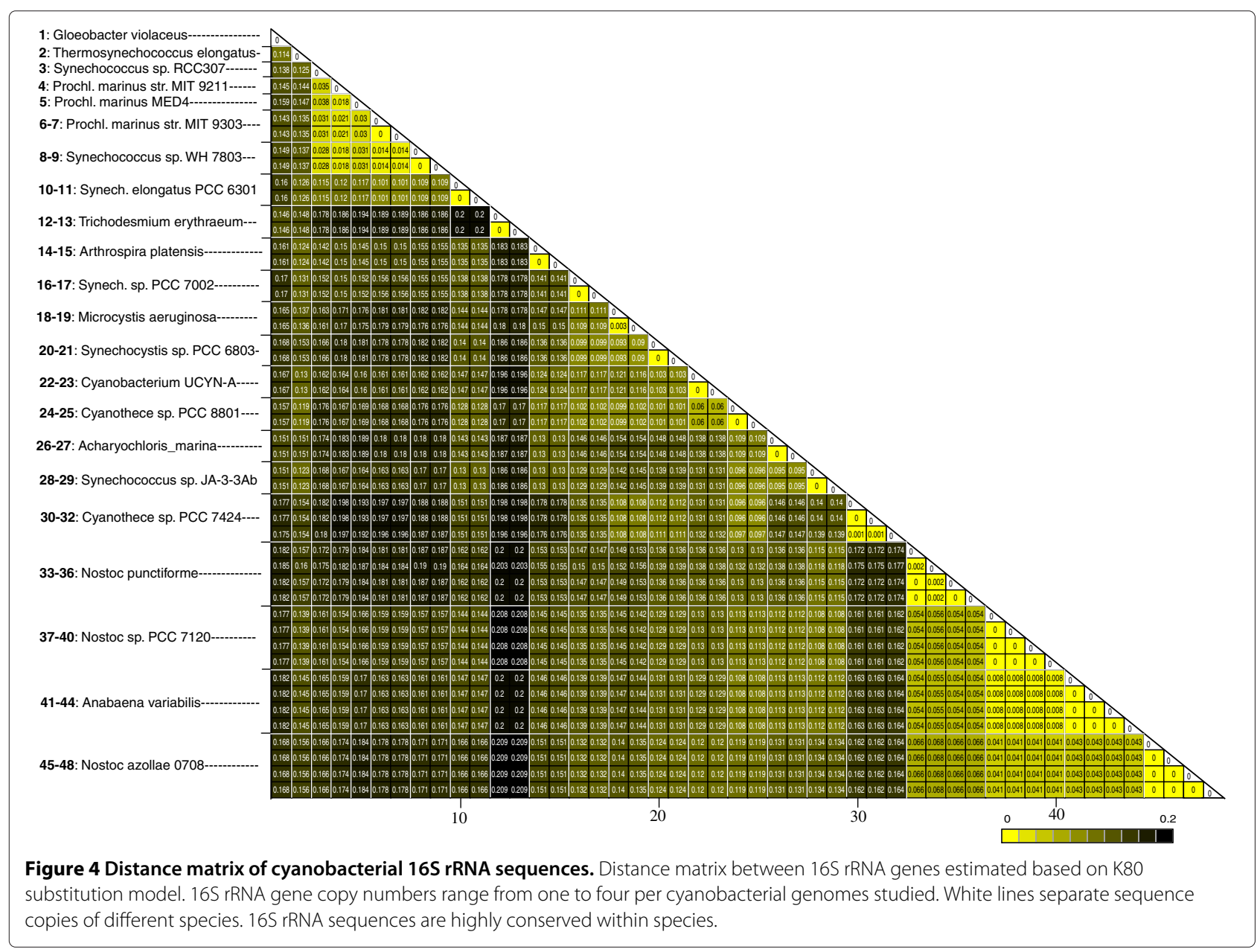


Table 2 Comparison of mean distances within cyanobacteria and to other eubacterial phyla

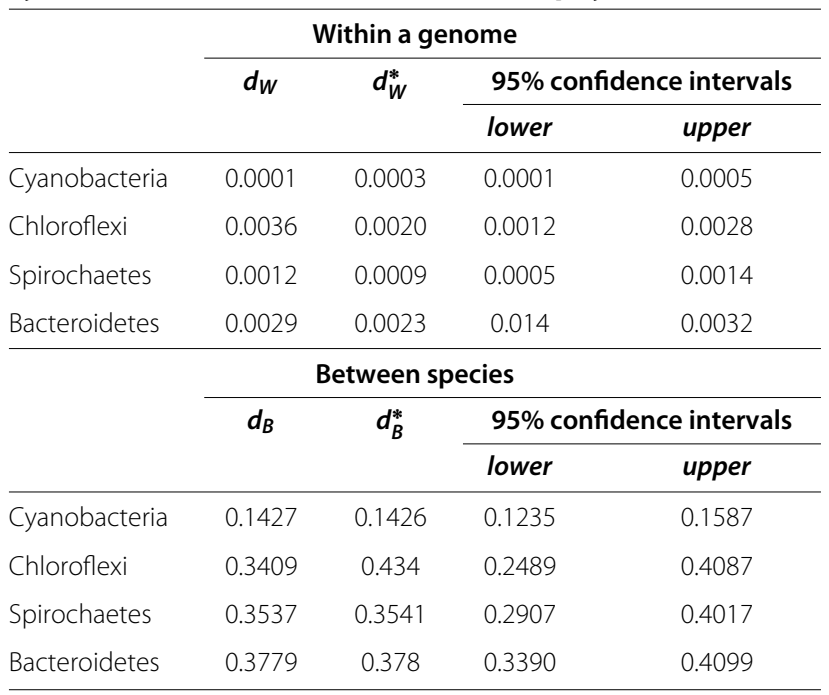

Comparison of mean distances in the different eubacterial phyla and the $95 \%$ confidence intervals of 10,000 mean values calculated from bootstrap samples. Confidence intervals do not overlap between cyanobacteria and the other eubacterial phyla. Distances of $16 \mathrm{~S}$ rRNA sequences are significantly smaller in cyanobacteria compared to the other prokaryotes. $d_{W}$ and $d_{B}$ : mean calculated from the original dataset including all distances. $\boldsymbol{d}_{W}^{*}$ and $\boldsymbol{d}_{B}^{*}$ : mean of 10,000 means calculated using bootstrap sampling.

and 8. Within the phylum Chloroflexi, species contain one to five 16S rRNA genes per genome. The phylogenetic tree is well supported by posterior probabilities. Previous phylogenetic studies have divided the phylum Chlorophlexi into several subdivisions [48,49], the majority of which is supported by our inferred tree. Distances of the 16S rRNA sequences within genomes and between species of Chloroflexi were significantly higher than found for cyanobacteria (Table 2). Mean distances of species belonging to the phylum Chloroflexi were $d_{W}=0.004$ within species, and showed a 10-fold difference compared to distances between species $\left(d_{B}=0.34\right)$. Chloroflexus auranticus and Chloroflexus sp. were the only species among the taxa analyzed in this study where 16S rRNA orthologs were more similar than their paralogs. Further comparison of mean distances for 16S rRNA sequences including phyla Spirochaetes and Bacteroidetes confirmed the significantly lower sequence variation in cyanobacteria. A comparison of the distributions of mean distances calculated from the bootstrap re-sampling show no overlap of the $95 \%$ confidence intervals of cyanobacteria and any of the other phyla (Additional files 4 and 5). Furthermore, within all studied phyla, mean distances for $16 \mathrm{~S}$ rRNA gene copies within a genome $\left(d_{W}\right)$ were smaller by at least one order of magnitude compared to mean distances for $16 \mathrm{~S}$ rRNA sequences between species $\left(d_{B}\right)$. Our results support $16 \mathrm{~S}$ rRNA as an adequate taxonomic marker for the species analyzed in this study and agree with previous findings of limited heterogeneity in $16 \mathrm{~S}$ rRNA [9].

\section{Evolution of 16S rRNA gene copies in cyanobacteria}

Two mechanisms may conserve sequences of gene copies: purifying selection and concerted evolution. These two can be distinguished by examining variation patterns in non-coding regions $[1,50]$. In the case of purifying selection, non-coding regions are thought to evolve neutrally, accumulating mutations over time due to genetic drift. If concerted evolution shapes gene copies, the entire gene sequence including non-coding regions and synonymous sites are homogenized. During this process, genes evolve in 'concert', which is commonly observed in plants and fungi [51,52] (Figure 6). Subsequently, paralogs show stronger similarities than orthologs, as a result of intragenomic homologous recombination [53].

The strong conservation of $16 \mathrm{~S}$ rRNA sequence copies in cyanobacteria and Eubacteria examined here suggests that 16S rRNA in these species is shaped by strong purifying selection and/or concerted evolution. Generally, it is assumed that ribosomal genes in Archaea and Eubacteria are shaped by concerted evolution [13]. 16S rRNA genes can be subdivided in strongly conserved and more variable regions. One would expect that if purifying selection acts as the major force for conservation of gene copies within a genome, some neutral variation should be detected in these variable regions. The extraordinary conservation of $16 \mathrm{~S}$ rRNA in cyanobacteria seems to indicate that concerted evolution is a more likely explanation. To verify this suggestion we examined variation in the internal transcribed spacer region, located between the 16S and 23S rRNA gene. Though previous studies have suggested conservation of some regions in the ITS sequence, several regions should not be affected by selection and evolve neutrally. If the entire ITS sequence showed the same degree of conservation as does the $16 \mathrm{~S}$ gene sequence, then purifying selection - which would only act on the functional parts - could be rejected as a driving force. However, the strong conservation found in cyanobacterial 16S rRNA gene sequences could not be confirmed for the ITS-regions of four cyanobacterial taxa (Additional file 9). For cyanobacteria and the eubacterial phyla studied here, both concerted evolution and strong purifying selection, appear to be the main contributing factors.

Although, cyanobacteria are assumed to be an ancient phylum which presumably raised oxygen levels in the atmosphere more than 2.3 billion years ago [54], variation in 16S rRNA copies is extremely low. Indeed, phylogenetic tree reconstructions for $16 \mathrm{~S}$ rRNA result in relatively short estimated branch lengths within this phylum, compared to other eubacterial phyla (Figure 2). Short evolutionary distances for $16 \mathrm{~S}$ rRNA sequences are consistent 


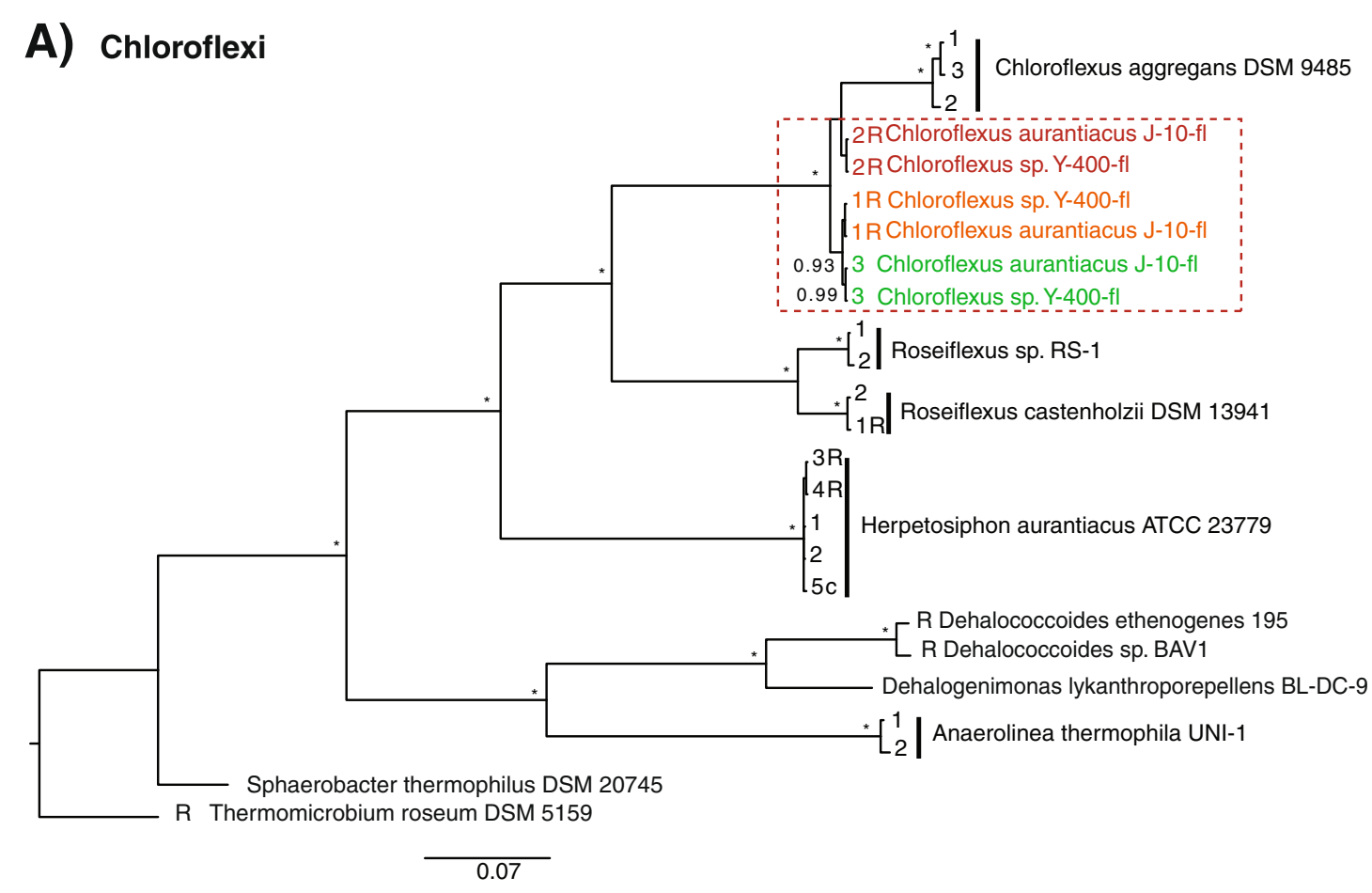

B)

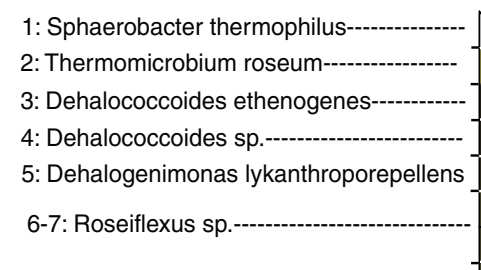

8-9: Roseiflexus castenholzii-

10-11: Anaerolinea thermophila-

12-14: Chloroflexus sp.

15-17: Chloroflexus aggregans

18-20: Chloroflexus aurantiacus-

21-25: Herpetosiphon aurantiacus

\section{S rRNA distances - Chloroflexi}

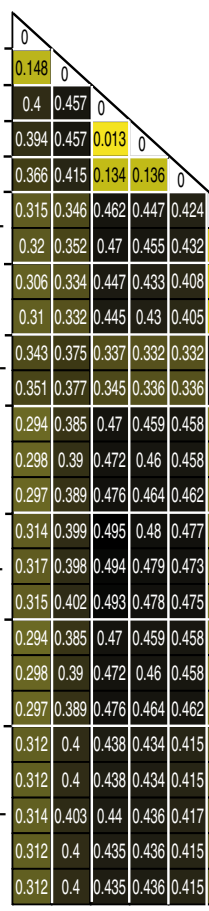

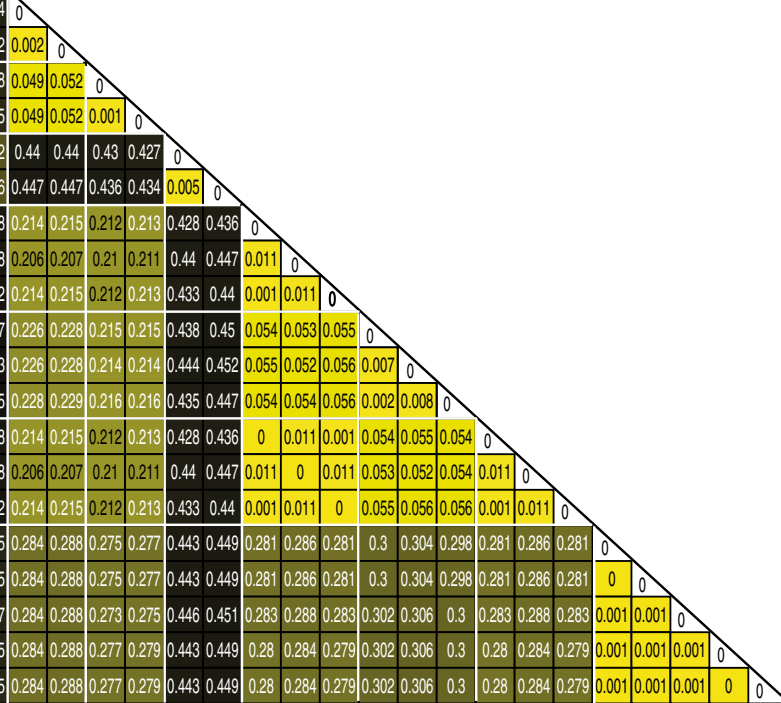

10

Figure 5 Phylogenetic tree and distance matrix of Chloroflexi including all 16S rRNA copies. (A) Phylogenetic tree of the eubacterial phylum Chloroflexi including all 16S rRNA copies, reconstructed using Bayesian analysis. On the nodes posterior probabilities $>0.90$ are displayed. Colored taxa mark species where $16 \mathrm{~S}$ rRNA copy numbers evolved rather via divergent evolution, than being homogenized within a strain via concerted evolution. The letter "R" denote gene copies that are positioned on the reverse DNA strand. (B) Distance matrix of Chloroflexi. Genetic distances have been estimated according to the K80 substitution model. White lines separate sequence copies of different species. 16S rRNA sequences are conserved within species, but exhibit more variation than found for cyanobacteria. 


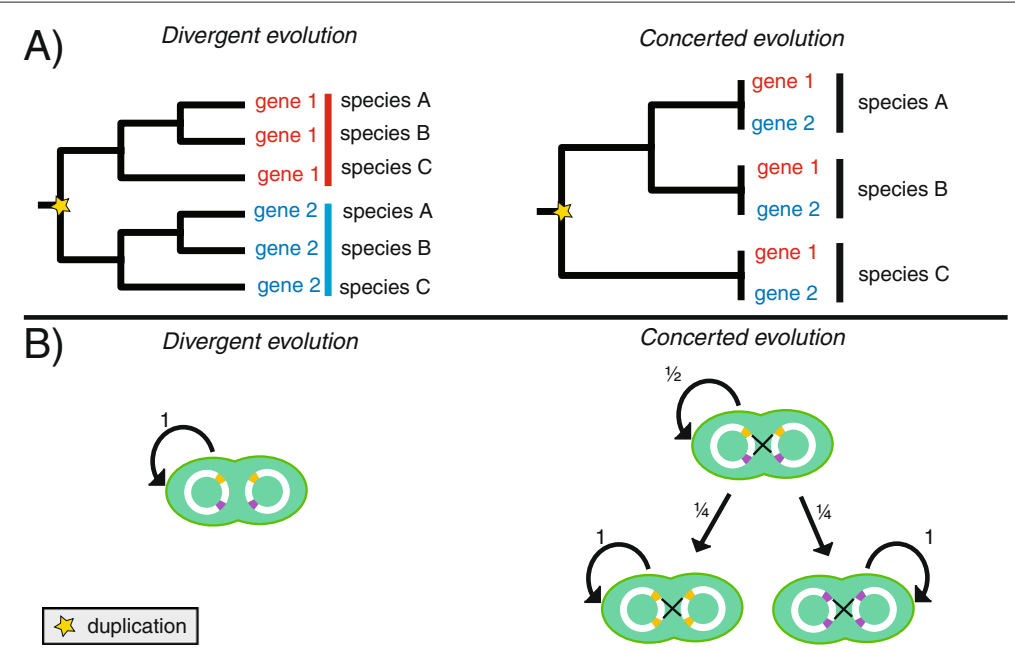

Figure 6 Divergent and concerted evolution. (A) The phylogenetic pattern of divergent and concerted evolution evolution. Paralogs and orthologs diverge at similar degrees in the first scenario, while they get frequently homogenized during concerted evolution. A cyanobacterial cell during cell division without homologous recombination. All daughter cells will exhibit the same chromosome as the mother cell. (B) Replication pattern during cell division under divergent and concerted evolution. If during cell devision homologous recombination takes place in half of the recombinants the daughter cells will exhibit the same chromosome as the mother. For the other half of recombinants, each gene copy has a $\frac{1}{4}$ chance of replacing the other. Once gene copies are identical homologous recombination cannot reverse the process. Hence if this process is repeated recursively at a population level, one gene copy will eventually get fixed.

with a pattern that has been found for morphological characters in cyanobacteria before. In 1994, J.W. Schopf compared the tempo and mode of evolution in cyanobacteria from the Precambrian, to evolutionary patterns observed in fossils during the Phanerozoic. The latter have been described by G.G. Simpson in his book "The tempo and mode of evolution" [55]. Schopf found that evolutionary predictions which Simpson made for metazoan fossils from the Phanerozoic, can also be applied to cyanobacteria. Morphologically, cyanobacteria seem to evolve not only at a "bradytelic", but "hypobradytelic" mode, meaning at exceedingly low evolutionary rates. Fossils from the Precambrian strongly resemble present morphotypes. The oldest undisputed cyanobacterial fossils date back circa 2.0 billion years $[18,19]$. Morphological appearance of these microfossils already suggests the presence of at least four of the morphological sections described by Castenholz [20]. It seems that cyanobacteria reached their maximum morphological complexity two billion years ago, and many of today's species could be described as so-called 'living fossils'. It remains to be seen whether the low evolutionary rates as seen in 16S rRNA sequences and morphological features, is also seen at the genomic and metabolic level. This question can be further resolved as further genomic sequences become available for the cyanobacteria.

\section{Conclusion}

Among 22 fully sequenced cyanobacterial taxa that were carefully chosen according to phylogenetic position and morphological characteristics, we identified 41 protein coding genes that occur as multiple highly conserved copies in at least one cyanobacterial species. Copy numbers of ribosomal genes show a significant correlation to cyanobacterial species that are capable of terminal differentiation. The formation of heterocysts, morphologically modified cells for nitrogen fixation, requires a strong increase in gene expression, for which an accumulation of ribosomes could be of potential advantage. Further testing would be required though, to make causal conclusions for increased rRNA operons in cyanobacteria belonging to section IV and V. Furthermore, phylogenetic analyses revealed a high conservation of $16 \mathrm{~S}$ rRNA copies within eubacterial species. Though this is true for all phyla that have been analyzed, cyanobacteria exhibit an exceptionally strong conservation. Comparison to variation in ITS regions point to concerted evolution via homologous recombination and purifying selection as the forces behind 16S rRNA sequence evolution. Comparison of interspecific genetic distances within several prokaryotic phyla, showed significantly lower variation of cyanobacterial 16S rRNA gene sequences. This suggests that $16 \mathrm{~S}$ rRNA gene sequences evolve by a 'hypobradytelic' mode of evolution, previously suggested for morphological characteristics in cyanobacteria [56].

\section{Methods}

\section{Data choice and description}

For this study we only used cyanobacterial taxa with fully sequenced and annotated genomes publicly available on 
GenBank (http://www.ncbi.nlm.nih.gov/genomes/lproks. cgi). Of those 42 genomes (as of August 2011), 36 belong to singlecelled strains, covering 10 different species in total. The remaining six genomes belong to multicellular strains, each representing another species. The taxon sampling was done to exclude a bias towards unicellular closely related cyanobacteria which are overrepresented in the genome-database [57]. Therefore, to cover the widest possible range of morphotypes, we selected one or more, fully sequenced taxa of each species for a total dataset of 22 cyanobacterial strains. More precisely, we included multiple strains of species Cyanothece sp.(2), Synechococcus sp.(4), and Prochlorococcus marinus(3), which, following the examination of previous phylogenies $[39,47,58,59]$, are assumed to add phylogenetic diversity. No outgroup was included in the phylogenetic analyses. Gloeobacter violceus has been shown to be closest to eubacterial outgroups [39]. Therefore, phylogenetic trees are represented accordingly.

\section{Identification of conserved paralogs and correlation to morphotypes}

In order to find genes with multiple copies, we applied the orthology prediction algorithm OMA [60] to the set of 22 complete cyanobacteria genomes. First we looked for clusters of highly conserved paralogous genes within each species. From the all-against-all pairwise sequence alignments computed by OMA, we selected pairwise hits within each species with an alignment score of at least 130 and minimum sequence identity of $\geq 98 \%, \geq 95 \%$ and $\geq 90 \%$. We then used these hits as edges in a homology graph, and identified clusters of highly conserved paralogs as connected components. Finally, we removed hits within a cluster if the pairwise distance differed significantly from the mean distance within the cluster. In the second step, we grouped detected homologous clusters across species using OMA alignments, but this time with a score cut-off of 180 and minimum sequence identity of $\geq 50 \%$. We further required that $\geq 0.8 \cdot n_{i} \cdot n_{j}$ of hits between any pair of clusters $i$ and $j$ be present in order to be considered, where $n_{i}, n_{j}$ is the number of genes in clusters $i$ and $j$, respectively. If a cluster in one genome grouped with several clusters in another genome, we chose the one with the lowest average pairwise distance. Again, homologous groups were extracted as connected components from the resulting graph. Finally, single orthologs from the OMA orthologous matrix (i.e, with no detected multiple copies within their originating genome) were matched and added to corresponding homologous groups.

We tested whether a correlation between cell differentiation and copy numbers could be observed for the identified genes. To do this, we devided cyanobacterial species into four different groups of cell differentiation
(G0-G3; see results). Five strains belong to G0, 12 taxa belong to G1, Tricodesmium is the only genus in G2, and four species belong to G3. For 16S rRNA genes additional data could be obtained from rrndb-database [45] (Additional file 3). Adding these data resulted in a taxon set of $16 \mathrm{~S}$ rRNA gene sequences as follows: five strains belonging to G0, 12 strains representing G1, Trichodesmium as the only species in G2 and 11 species in G3. Spearman's rank and Pearson's correlation coefficients were applied in order to estimate associations between conserved copy numbers and morphological groups (G0-G3), using R-software. Correlations with a p-value $<0.01$ were considered to be significant.

\section{Phylogenetic analyses}

We conducted separate phylogenetic analyses of $16 \mathrm{~S}$ rRNA gene sequences of cyanobacteria (Table 1) and four different eubacterial phyla (Additional file 10). For all taxa included in the phylogenetic trees, full genome sequences were available. All sequences were downloaded from GenBank [61]. For cyanobacteria two phylogenetic trees were reconstructed. One including a single $16 \mathrm{~S}$ rRNA sequence per taxon and another including all $16 \mathrm{~S}$ rRNA copies per taxon. Final taxon sets included 22 sequences in the first case and 48 sequences in the latter. The datasets were aligned using Clustal-X software with default settings [62] (1,325nt incl. gaps). Gaps were excluded from the analysis. Phylogenetic reconstructions were done using Bayesian analysis as implemented in MrBayes software [63]. Two Metropolis coupled Markov Chain Monte Carlo $\left(M C^{3}\right)$ searches were run for $10^{7}$ generations each using three heated and one cold chain. Figure 1 and Figure 2 show the consensus trees of 16,002 trees that were sampled every 1,000th generation from the $M C^{3}$ searches, excluding the first 2,000 trees of each run (burn-in). At that point the log probabilities reached stationarity and average standard deviation of split frequencies were below 0.02. Performance of the MCMC and stationarity of the parameters were checked using Tracer v1.5 [64]. Effective Sample Sizes (ESS) were all above 200, supporting a well mixed MCMC run.

Phylogenetic analysis described for cyanobacteria was equally conducted for the phyla Auificae, Bacteroidetes, Chloroflexi and Spirochaetes. The non-cyanobacterial phylogenetic trees were reconstructed including all $16 \mathrm{~S}$ rRNA gene copies of each taxon. $M C^{3}$ analyses were run for $10^{6}$ generations. The first 200,000 generations of each run were discarded as a burn-in. Parameters and trees were sampled every 1,000 th generation resulting in a final set of 1,602 trees. The resulting Bayesian consensus trees for each phylum with posterior probabilities displayed at the nodes, have been visualized with FigTree v1.3.1 [65]. 


\section{Molecular distance analyses}

For each set of aligned 16S rRNA gene sequences, distance matrices were calculated applying a K80 substitution model as implemented in the program baseml of PAML v4.3 [66]. The same was done for the internal transcribed spacer region (ITS) in cyanobacteria (Additional file 9). The resulting numeric matrices were imaged as color matrices using the R-package "plotrix" [67]. The color gradient of each matrix was scaled by the matrix's minimum and maximum values. Mean distances were calculated within strains (between paralogs; $d_{W}$ ) and between strains (between orthologs; $d_{B}$ ), for each phylum. Significant differences in mean distances were confirmed with bootstrap re-samplings of independent values from the original dataset. To estimate significant differences of mean distances within species $\left(d_{W}\right)$, independent distance values were sampled 10,000 times for each species. Bootstrap re-sampling was done on each of these sample sets. Mean distances were hence calculated and their distribution plotted in a histogram (Additional file 4). The resulting overall mean, $d_{W}^{*}$ of the distributions, as well as $95 \%$ confidence intervals are presented in Table 2 . To confirm potential differences of mean distances between species $\left(d_{B}\right)$ compared to other phyla, independent values were sampled 10,000 times. These datasets were re-sampled and mean distances calculated. The distributions are displayed in Additional file 5. The resultant overall mean, $d_{B}^{*}$ of each distribution, as well as 95\% confidence intervals are shown in Table 2. Independence of distance estimations was assumed if from the corresponding matrix each column and row was only chosen once.

\section{Additional files}

Additional file 1: Identified gene copies. The sheet contains Information on 41 gene copies and their presence in 22 cyanobacterial species. Amino acid sequences of the coded proteins exhibit $98 \%$ similarity within a genome and $50 \%$ across species.

Additional file 2: 16S rRNA gene copy data including data from the rrndb-database. Table with information on 165 rRNA copy numbers including data received from the rrnDB database [45] marked $(*)$.

Additional file 3: Distribution of $16 \mathrm{~S}$ rRNA copy numbers using additional data from rrndb3. Boxplot representations of the 16S rRNA gene copy number distribution across the previously defined morphological groups. Additional data on 165 rRNA copy numbers were received from the rrndb-database [45]. Spearman's rank correlation coefficient $(\rho)$ and Pearson's correlation coefficient (R) are displayed above the graph. A strong correlation of 16S rRNA gene copies to terminally differentiated cyanobacteria is supported.

Additional file 4: Distribution of mean distances within species of bootstrap samples for the different eubacterial phyla. The distribution of mean distances of the bootstrap samples presented as a histogram. The 95\% confidence intervals between cyanobacteria and Chloroflexi, Spirochaetes and Bacteroidetes do not overlap. Cyanobacterial 16S rRNA gene sequence variation within species is significantly lower.
Additional file 5: Distribution of mean distances between species of bootstrap samples for the different eubacterial phyla. The distribution of mean distances of the bootstrap samples presented as a histogram. The 95\% confidence intervals between cyanobacteria and the other eubacterial phyla do not overlap. Cyanobacterial 16S rRNA gene sequence variation between species are significantly lower.

Additional file 6: Phylogenetic tree and distance matrix of Spirochaetes. (A) Phylogenetic tree of the eubacterial phylum Spirochaetes including all 165 rRNA gene copies, reconstructed using Bayesian analysis. On the nodes posterior probabilities $>0.90$ are displayed. The letter " $\mathrm{R}$ " denote gene copies that are positioned on the reverse DNA strand. (B) Distance matrix of Spirochaetes. Genetic distances have been estimated according to the K80 substitution model. White lines separate sequence copies of different species.

Additional file 7: Phylogenetic tree of Bacteroidetes. Phylogenetic tree of the eubacterial phylum Bacteroidetes including all 16S rRNA gene copies, reconstructed using Bayesian analysis. On the nodes posterior probabilities $>0.90$ are displayed.The letter " $\mathrm{R}$ " denote gene copies that are positioned on the reverse DNA strand.

Additional file 8: Distance matrix of Bacteroidetes. Genetic distances have been estimated according to the K80 substitution model. White lines separate sequence copies of different species.

Additional file 9: Distance matrix of cyanobacterial ITS-region. Distance matrix of the internal transcribed spacer sequence region in cyanobacteria. Genetic distances have been estimated according to the K80 substitution model. White lines separate sequence copies of different species. Distances $\geq 5.7$ are displayed by the same blue color.

Additional file 10: Data of $16 \mathrm{~S}$ rRNA gene sequences of the different eubacterial phyla. Species nomenclature, genome sizes, $16 \mathrm{~S}$ rRNA gene copy numbers and accession numbers from the eubacterial taxa used in this study.

Competing interests

The authors declare that they have no competing interests.

\section{Authors' contributions}

$\mathrm{BES}$ and $\mathrm{HCB}$ conceived the study; BES gathered data; BES and DAD conducted analyses; BES, DAD, MA and HCB designed research and wrote the paper. All authors read and approved the final manuscript.

\section{Acknowledgements}

For statistical advice and support we would like to thank Erik Postma. Furthermore, we would like to thank Dr. Manuela Filippini Cattani, Dr. Miroslav Svercel and Valentina Rossetti for helpful comments on various versions of the manuscript.

\section{Author details}

${ }^{1}$ Institute of Evolutionary Biology and Environmental Studies, University of Zurich, Winterthurerstr. 190, 8057 Zurich, Switzerland. ${ }^{2}$ School of Earth Sciences, University of Bristol, Wills Memorial Building, Queens Road, Bristol BS8 1RJ, UK. ${ }^{3}$ Computational Biochemistry Research Group, Swiss Federal Institute of Technology, Universitätstrasse 6, 8092 Zurich, Switzerland. ${ }^{4}$ Swiss Institute of Bioinformatics, Universitätstrasse 6, 8092 Zurich, Switzerland.

Received: 18 January 2012 Accepted: 25 June 2012

Published: 15 August 2012

\section{References}

1. Zhang JZ: Evolution by gene duplication: an update. Trends Ecol \& Evolut 2003, 18(6):292-298.

2. Schrider DR, Hahn MW: Gene copy-number polymorphism in nature. Proc R Soc B-biol Sci 2010, 277(1698):3213-3221.

3. Graubert TA, Cahan P, Edwin D, Selzer RR, Richmond TA, Eis PS, Shannon WD, Li X, McLeod HL, Cheverud JM, Ley TJ: A high-resolution map of segmental DNA copy number variation in the mouse genome. Plos Genet 2007, 3:e3.

4. Springer NM, Ying K, Fu Y, Ji TM, Yeh CT, Jia Y, Wu W, Richmond T, Kitzman J, Rosenbaum H, Iniguez AL, Barbazuk WB, Jeddeloh JA, Nettleton D, 
Schnable PS: Maize Inbreds exhibit high levels of Copy Number Variation (CNV) and Presence/Absence Variation (PAV) in genome content. Plos Genet 2009, 5(11):e1000734.

5. Carreto L, Eiriz MF, Gomes AC, Pereira PM, Schuller D, Santos MAS: Comparative genomics of wild type yeast strains unveils important genome diversity. BMC Genomics 2008, 9:524

6. Beckmann JS, Estivill X, Antonarakis SE: Copy number variants and genetic traits: closer to the resolution of phenotypic to genotypic variability. Nature Rev Genet 2007, 8(8):639-646.

7. Perry GH: The evolutionary significance of copy number variation in the human genome. Cytogenetic Genome Res 2008, 123(1-4):283-287.

8. Perry GH, Dominy NJ, Claw KG, Lee AS, Fiegler H, Redon R, Werner J, Villanea FA, Mountain JL, Misra R, Carter NP, Lee C, Stone AC: Diet and the evolution of human amylase gene copy number variation. Nat Genet 2007, 39(10):1256-1260

9. Coenye $T$, Vandamme P: Intragenomic heterogeneity between multiple $16 \mathrm{~S}$ ribosomal RNA operons in sequenced bacterial genomes. RFEMS Microbiol Lett 2003, 228:45-49.

10. Pei AY, Oberdorf WE, Nossa CW, Agarwal A, Chokshi P, Gerz EA, Jin Z, Lee P, Yang L, Poles M, Brown SM, Sotero S, DeSantis T, Brodie E, Nelson K, Pei Z: Diversity of $16 \mathrm{~S}$ rRNA genes within individual Prokaryotic genomes. Appl Environ Microbiol 2010, 76(12):3886-3897.

11. Klappenbach JA, Dunbar JM, Schmidt TM: $r$ RNA operon copy number reflects ecological strategies of bacteria. Appl Environ Microbiol 2000, 66(4):1328-1333.

12. Tourova TP: Copy number of ribosomal operons in prokaryotes and its effect on phylogenetic analyses. Microbiology 2003, 72(4):389-402.

13. Liao DQ: Gene conversion drives within genic sequences: concerted evolution of ribosomal RNA genes in bacteria and archaea. $\mathrm{MO} / \mathrm{EvO}$ 2000, 51(4):305-317.

14. Rastogi R, Wu M, DasGupta I, Fox GE: Visualization of ribosomal RNA operon copy number distribution. BMC Microbiol 2009, 9:208

15. Maniloff J: The minimal cell genome: "On being the right size". Proc Nat Acad SciU S A 1996, 93(19):10004-10006.

16. Marais GAB, Calteau A, Tenaillon O: Mutation rate and genome reduction in endosymbiotic and free-living bacteria. Genetica 2008, 134(2):205-210

17. Kuo $\mathrm{CH}$, Moran NA, Ochman $\mathrm{H}$ : The consequences of genetic drift for bacterial genome complexity. Genome Res 2009, 19(8):1450-1454

18. Hofmann HJ: Precambrian Microflora, Belcher Islands, Canada Significance and Systematics. J Paleontology 1976, 50(6):1040-1073.

19. Amard B, BertrandSarfati J: Microfossils in $\mathbf{2 0 0 0}$ Ma old cherty stromatolites of the Franceville Group, Gabon. Precambrian Res 1997, 81(3-4):197-221.

20. Castenholz RW: Cyanobacteria. In Bergey's Manual of Systematic Bacteriology: The Archaea and the Deeply Branching and Phototropic Bacteria: Cyanobacteria. Edited by Garrity GM. New York: Springer Verlag; 2001

21. Giovannoni SJ, Turner S, Olsen GJ, Barns S, Lane DJ, Pace NR: Evolutionary relationships Among Cyanobacteria and green Chloroplasts. J Bacteriol 1988, 170(8):3584-3592.

22. Turner S, Pryer KM, Miao VPW, Palmer JD: Investigating deep phylogenetic relationships among cyanobacteria and plastids by small submit rRNA sequence analysis. J Eukaryotic Microbiol 1999, 46(4):327-338.

23. Ishida T, Watanabe MM, Sugiyama J, Yokota A: Evidence for polyphyletic origin of the members of the orders of Oscillatoriales and Pleurocapsales as determined by $16 \mathrm{~S}$ rDNA analysis. Fems Microbiol Lett 2001, 201:79-2.

24. Litvaitis MK: A molecular test of cyanobacterial phylogeny: inferences from constraint analyses. Hydrobiologia 2002, 468(1-3):135-145

25. Gugger MF, Hoffmann L: Polyphyly of true branching cyanobacteria (stigonematales). Int J Syst Evolutionary Microbiol 2004, 54:349-357.

26. Tomitani A, Knoll AH, Cavanaugh CM, Ohno T: The evolutionary diversification of cyanobacteria: Molecular-phylogenetic and paleontological perspectives. Proc Nat Acad Sci U S A 2006, 103(14):5442-5447.

27. Fredriksson C, Bergman B: Ultrastructural characterisation of cells specialised for nitrogen fixation in a non-heterocystous cyanobacterium, Trichodesmium spp. Protoplasma 1997 197(1-2):76-85.

28. Berman-Frank I, Lundgren $\mathrm{P}$, Chen $Y B$, Kupper $\mathrm{H}$, Kolber Z, Bergman $\mathrm{B}$ Falkowski $P$ : Segregation of nitrogen fixation and oxygenic photosynthesis in the marine cyanobacterium Trichodesmium. Science 2001, 294(5546):1534-1537.

29. El-Shehawy R, Lugomela C, Ernst A, Bergman: Diurnal expression of het $R$ and diazocyte development in the filamentous non-heterocystous cyanobacterium Trichodesmium erythraeum. Microbiology-sgm 2003, 149:1139-1146.

30. Engene N, Coates RC, Gerwick WH: 16S rRNA gene heterogeneity in the filamentous marine cyanobacterial genus Lyngbya. J Phycol 2010, 46(3):591-601.

31. Engene N, Gerwick WH: Intra-genomic 16S rRNA gene heterogeneity in cyanobacterial genomes. Fottea 2011, 11:17-24.

32. Noller HF, Woese CR: Secondary Structure of 16S-ribosomal RNA. Science 1981, 212(4493):403-411.

33. Olsen GJ, Woese CR: Ribosomal-RNA - a key to Phylogeny. Faseb J 1993, 7:113-123.

34. Olivier A, Lee HY, Côté JC: Study of the heterogeneity of 16S rRNA genes in $\gamma$-proteobacteria: Implications for phylogenetic analysis. J Gen Appl Microbiol 2005, 51:395-405

35. Nakamura Y, Kaneko T, Sato S, Mimuro M, Miyashita H, Tsuchiya T, Sasamoto S, Watanabe A, Kawashima K, Kishida Y, Kiyokawa C, Kohara M, Matsumoto M, Matsuno A, Nakazaki N, Shimpo S, Takeuchi C, Yamada M, Tabata S: Complete genome structure of Gloeobacter violaceus PCC 7421, a cyanobacterium that lacks thylakoids. Dna Res 2003 10(4):137-145.

36. Swingley WD, Blankenship RE, Raymond J: Integrating markov clustering and molecular phylogenetics to reconstruct the cyanobacterial species tree from conserved protein families. Mol Biol Evol 2008, 25(4):643-654.

37. Gupta R, Mathews D: Signature proteins for the major clades of Cyanobacteria. BMC Evolutionary Biol 2010, 10:24.

38. Criscuolo A, Gribaldo S: Large-Scale Phylogenomic Analyses Indicate a Deep Origin of Primary Plastids within Cyanobacteria. Mol Biol Evol 2011, 28(11):3019-3032.

39. Schirrmeister $B E$, Antonelli $A$, Bagheri $\mathrm{HC}$ : The origin of multicellularity in cyanobacteria. BMC Evolutionary Biol 2011, 11:45.

40. Aziz RK, Breitbart M, Edwards RA: Transposases are the most abundant, most ubiquitous genes in nature RID B-2918-2009. Nucleic Acids Res 2010, 38(13):4207-4217

41. Allewalt JP, Bateson MM, Revsbech NP, Slack K, Ward DM: Effect of temperature and light on growth of and photosynthesis by Synechococcus isolates typical of those predominating in the octopus spring microbial mat community of Yellowstone National Park. Appl Environ Microbiol 2006, 72:544-550.

42. Steunou AS, Bhaya D, Bateson MM, Melendrez MC, Ward DM, Brecht E, Peters JW, Kuhl M, Grossman AR: In situ analysis of nitrogen fixation and metabolic switching in unicellular thermophilic cyanobacteria inhabiting hot spring microbial mats RID A-1977-2009. Proc Nat Acad SciUSA 2006, 103(7):2398-2403.

43. Ferris MJ, RuffRoberts AL, Kopczynski ED, Bateson MM, Ward DM: Enrichment culture and microscopy conceal diverse thermophilic Synechococcus populations in a single hot spring microbial mat habitat. App/ Environ Microbiol 1996, 62(3):1045-1050.

44. Rippka R, Waterbury J, Cohenbazire G: Cyanobacterium Which Lacks Thylakoids. Arch Microbiol 1974, 100(4):419-436

45. Lee ZM, Bussema C, Schmidt TM: rrnDB: documenting the number of rRNA and tRNA genes in bacteria and archaea. Nucleic Acids Res 2009, 37:D489-D493.

46. Adams DG: Heterocyst formation in cyanobacteria. Curr Opin Microbiol 2000, 3(6):618-624.

47. Blank CE, Sánchez-Baracaldo P: Timing of morphological and ecological innovations in the cyanobacteria - a key to understanding the rise in atmospheric oxygen. Geobiology 2010 $\mathbf{8 : 1 - 2 3}$

48. Bjornsson L, Hugenholtz P, Tyson GW, Blackall LL: Filamentous Chloroflexi (green non-sulfur bacteria) are abundant in wastewater treatment processes with biological nutrient removal. Microbiology-Sgm 2002, 148:2309-2318. 
49. Costello EK, Schmidt SK: Microbial diversity in alpine tundra wet meadow soil: novel Chloroflexi from a cold, water-saturated environment. Environ Microbiol 2006, 8(8):1471-1486.

50. Nei M, Rogozin IB, Piontkivska H: Purifying selection and birth-and-death evolution in the ubiquitin gene family. Proc Nat Acad Sci U S A 2000, 97(20):10866-10871.

51. Sang T, Crawford DJ, Stuessy TF: Documentation of Reticulate Evolution In Peonies (peonia) Using Internal Transcribed Spacer Sequences of Nuclear Ribosomal Dna - Implications For Biogeography and Concerted Evolution. Proc Nat Acad Sci U S A 1995, 92(15):6813-6817.

52. Ganley ARD, Kobayashi T: Highly efficient concerted evolution in the ribosomal DNA repeats: Total rDNA repeat variation revealed by whole-genome shotgun sequence data. Genome Res 2007, 17(2):184-191.

53. Santoyo G, Romero D: Gene conversion and concerted evolution in bacterial genomes. Fems Microbiol Rev 2005, 29(2):169-183.

54. Bekker A, Holland HD, Wang PL, Rumble D, Stein HJ, Hannah JL, Coetzee $\mathrm{LL}$, Beukes NJ: Dating the rise of atmospheric oxygen. Nature 2004, 427:117-120.

55. Simpson GG: Tempo and Mode in Evolution. New York: Columbia University Press; 1944

56. Schopf JW: Disparate Rates, Differing Fates - Tempo and Mode of Evolution Changed From the Precambrian To the Phanerozoic. Proc Nat Acad Sci U S A 1994, 91(15):6735-6742.

57. Schirrmeister BE, Anisimova M, Antonelli A, Bagheri HC: Evolution of cyanobacterial morphotypes: Taxa required for improved phylogenomic approaches. Commun Integr Biol 2011, 4:424-427.

58. Rocap G, Larimer FW, Lamerdin J, Malfatti S, Chain P, Ahlgren NA, Arellano A, Coleman M, Hauser L, Hess WR, Johnson ZI, Land M, Lindell D, Post AF, Regala W, Shah M, Shaw SL, Steglich C, Sullivan MB, Ting CS, Tolonen A, Webb EA, Zinser ER, Chisholm SW: Genome divergence in two Prochlorococcus ecotypes reflects oceanic niche differentiation. Nature 2003, 424:1042-1047.

59. Mazard SL, Fuller NJ, Orcutt KM, Bridle O, Scanlan DJ: PCR analysis of the distribution of unicellular cyanobacterial diazotrophs in the Arabian Sea. Appl Environ Microbiol 2004, 70(12):7355-7364

60. Roth ACJ, Gonnet GH, Dessimoz C: Algorithm of OMA for large-scale orthology inference. BMC Bioinformatics 2008, 9:518.

61. Benson DA, Karsch-Mizrachi I, Lipman DJ, Ostell J, Wheeler DL: GenBank. Nucleic Acids Res 2008, 36:D25-D30.

62. Thompson JD, Gibson TJ, Plewniak F, Jeanmougin F, Higgins DG: The CLUSTAL_X windows interface: flexible strategies for multiple sequence alignment aided by quality analysis tools. Nucleic Acids Res 1997, 25(24):4876-4882.

63. Ronquist F, Huelsenbeck JP: MrBayes 3: Bayesian phylogenetic inference under mixed models. Bioinformatics 2003, 19(12):1572-1574.

64. Rambaut A, Drummond AJ: Tracer v1.4 [online]. Available at: [http:// tree.bio.ed.ac.uk/software/tracer/] 2007.

65. Rambaut A: FigTree v1.3.1 [online]. Available at: [http://tree.bio.ed.ac. uk/software/figtree] 2009.

66. Yang ZH: PAML 4: Phylogenetic analysis by maximum likelihood. $\mathrm{Mol}$ Biol Evol 2007, 24(8):1586-1591.

67. Lemon J: Plotrix: a package in the red light district of R. R-news 2006 6(4):8-12.

doi:10.1186/1471-2180-12-177

Cite this article as: Schirrmeister et al.: Gene copy number variation and its significance in cyanobacterial phylogeny. BMC Microbiology 2012 12:177.

Submit your next manuscript to BioMed Central and take full advantage of:

- Convenient online submission

- Thorough peer review

- No space constraints or color figure charges

- Immediate publication on acceptance

- Inclusion in PubMed, CAS, Scopus and Google Scholar

- Research which is freely available for redistribution

Submit your manuscript at www.biomedcentral.com/submit
O) Biomed Central 